\title{
Promote Safety Culture and Enhance Safety Performance through Safety Behaviour
}

\author{
Lebbaeus Asamani
}

\begin{abstract}
Protection of workers against harm and sicknesses is a fundamental human right, irrespective of where the individual works. Most workplace safety and health research concentrate on the industrial and formal or corporate work settings, with very little attention given to the informal sector, especially informal agriculture. The present paper investigated safety behaviour as a mediating variable in the relationship between safety culture and safety performance of rice farm worker. The study was a cross-sectional survey, involving 469 respondents ( 347 males and 122 females), with an average age of 45.96 years and $\mathbf{1 3 . 6 5}$ years of rice farming experience. The data was analysed with the Partial Least Square Structural Equation Modelling. The paper found safety culture to be a strong predictor of safety behaviour, and a moderate predictor of safety performance. Also, safety behaviour had a competitive partial mediating effect on the relationship between safety culture and safety performance. Contrary to expectation, safety behaviour had a positive relationship with safety performance, and safety culture was a better predictor of safety performance than safety behaviour. The results were discussed in light of the socio-cultural subsystem model and recommendation for research, practice and policy proffered.
\end{abstract}

Index Terms - Safety culture of farm workers, safety performance in agriculture, promotion of safety behaviour, safety compliance, safety participation.

\section{INTRODUCTION}

The health and wellbeing of workers is of crucial importance to the individual as well as the organization. It is therefore imperative that organizational and individual factors that have implication for the health of employees are rigorously investigated and brought to the fore. No matter the sector of work or the work settings, there are general and peculiar health and safety concerns that must be addressed to ensure the work experiences of the workers are optimized. Reference [19] indicated that workplace safety had been neglected in favour of enhanced productivity for years, until more recent years that concerns for safety practices and wellbeing of workers have become one of the priority areas of organizations. This redirection of attention by organizations, researchers and safety practitioners were as a result of the occurrence of a number of devastating industrial accidents that led catastrophes damages and deaths [19], [67]. The present study investigated how occupational safety culture relates to safety performance of rice farm workers through their safety behaviour.

The International Labour Organisation (ILO), the World

Published on July 13, 2020.

L. Asamani, University of Cape Coast, Ghana

(corresponding e-mail: lebbaeus.asamani@ ucc.edu.gh)
Health Organisation (WHO), the 1992 Constitution of Ghana, as well as the Labour Act (Act 651, 2003) of Ghana, all underscore the fact that protection of workers against harm and sicknesses is a fundamental human right, irrespective of where the individual works. For instance, the International Labour Organisation (ILO) constitution indicates in the preamble that: "The protection of the worker against sickness, diseases and injury arising out of employment is fundamental element of social justice." This is supported by the World Health Organisation which indicated that: "Occupational safety and health is human right and decent work eventually is safe work (WHO, 2010: p. 1). The UN also emphasized this point when the former Secretary General stated that "Safety and health at work is not only a sound economic policy - it is a basic human right" (Kofi Annan); and the Labour Act of Ghana, (Act 651, 2003, Article 118:1) also stipulates that it is obligatory for the employer to "ensure that every worker employed in Ghana works under satisfactory, safe and healthy conditions" at their workplace, whether in the farm, office or in the factory or shop. The Labour Act of Ghana (Act 651, 2003) defines a workplace as "any place where a worker needs to be or to go by reason of his or her work which is under the direct or indirect control of the worker" (p. 52).

Ensuring that the work environment and conditions are safe and conducive for the worker is critical for the promotion of healthy workforce and progressive society. Reference [53] argued that the work environment and the nature of work itself have enormous implications for the physical and psychological health of workers. Occupational accidents present psychological and physical health challenges to the victims as well as others who witnessed the incident. The ripple effects of workplace health and safety incidents on employees are costly to the individual employees, their families, employers and the nation as a whole. Safety science researchers, management practitioners and workers therefore need to take investigations into factors that can facilitate health and safety at all workplace seriously, not only corporate institution, but the informal sectors as well. The aim of this paper was to investigate the intervening role of safety behaviour in the relationship between workplace safety culture and safety performance of rice farm workers in Southern Ghana.

\section{A. Statement of the Problem}

Review of the safety science literature suggests that most workplace safety and health research concentrate on the industrial and formal or corporate work settings, and areas such as construction, mining, oil and gas. The informal sector, especially, production agriculture has seen very little safety science research in Ghana. Limited research in the 
informal sector sighted were in areas such as wood industry [49], [24], [58], female work-related ill-health [5], [42], vehicle repair artisans [60], market and street traders [2], household survey of occupational injuries [59], crop production [56].

As observed in [11] and [62] in studies involving cocoa farmers in Ghana, farming is among the most hazardous occupations. Estimates [41] indicate that out of a total of 335,000 fatal workplace accidents worldwide, there are about 170,000 deaths among agriculture workers. Statistics from [85] also indicate that agriculture ranks among the most hazardous industries and farmers are at very high risk for fatal and nonfatal injuries. Indeed, the 1992 constitution of Ghana states that "every person has the right to work under safe and healthy conditions" (section 24: 1). The informal sector is estimated to have provided employment to $91.3 \%$ of the total workforce worldwide [37]. The Ghanaian informal sector constitutes about $86.1 \%$ [29]. Furthermore, specific to the agriculture sector, $53.9 \%$ of the world's workforce is engaged in the informal sector [37], [44] and $60 \%$ of this number is in the developing countries, like Ghana.

Furthermore, there has been no study cited in the literature in relation to health and safety of rice farm workers in Ghana. Even though safety behaviour and safety culture studies abound in the formal sector, there is paucity in the informal sector and particularly, production agriculture. Safety culture has been cited as a major contributory factor of accidents by many industrial accident investigations, and generally organisations with a strong positive safety culture are more effective at ensuring safety and having better safety performance [68], [81]. Meanwhile, there has not been any study cited in the literature that investigated the safety culture of rice farmers in Ghana. The present paper therefore contributed to the literature and investigated the intervening mechanism of safety behaviour in the way safety culture relates to safety performance with a sample of rice farm workers drawn from major irrigation schemes in Southern Ghana.

\section{B. Theoretical Framework}

\section{Socio-cultural subsystem model}

The socio-cultural subsystem model provided theoretical basis and context that guided this paper. This model stems from the social system theory [52], takes into account the nature of relationship existing between an organization's culture and the culture of the society the organizations operates in and workers come from. As [70] aptly observed, contemporary societies and organizations exist as complex differentiated sub-systems, linked together with communications systems. This paper argues that modern organizations and workplaces are miniature social system, and the cultural norms and values of the society within which the organization operates have influence for the behaviour of the workers, including their safety behaviour.

This paper examined the safety culture that existed in the rice irrigation schemes, and how the safety culture related to the safety behaviour of the workers. Organizational safety culture is a sub of the overall organizational culture [84]. According to [3], culture explains the bases for an individual's behaviour and attitude at work. Given that numerous subgroup differences in risk perceptions exist within the same culture, work setting and occupation, it is safe to argue that social construction of risk beliefs are context bound [13] and influenced by cultural systems.

\section{Safety Behaviour and Safety Performance}

There seems to be a conceptual ambiguity and inconsistency regarding the use of the concepts, safety behaviour and safety performance in the literature. While some researchers used safety related behaviour sample as a measure safety performance, others used safety outcome measures (such as number of accidents, injuries, nearmisses, etc). Notwithstanding this, the rate of accident tends to be the most commonly used independent measures of safety performance in literature. Safety related behaviour sample is referred to as safety behaviour in many studies and considered to be the immediate antecedent of safety performance. This paper clearly distinguished between the two concepts, denoting safety related behaviours as safety behaviour, while quantitative safety outcomes are referred to as safety performance here. Safety behaviour is conceptually a leading indicator while, safety performance is a lagging indicator of safety. The distinction is necessary because results of investigations involving relationships between safety related behaviour or safety culture and safety performance (as used here) may show variability depending on how the antecedents were measured, the specific safety performance measures used, and whether antecedents were compared to concurrent or future safety performance.

Reference [30] differentiated two types of safety behaviour based on distinction between task and contextual performance. The two-component safety behaviour, which was used in this study, consists of safety compliance and safety participation. Consistent with the conceptualisation employed in this study [46] separated safety behaviour and safety performance and examined safety climate as an antecedent of safety behaviour (safety compliance and safety participation), as well as safety performance (injuries and near misses). The results indicated that there is a positive relationship between safety climate and safety behaviour. It was also found that both safety compliance and participation were positively related to safety performance. For instance, [61] did not find significant relationship between safety culture and safety performance when performance was measured using industrial safety accident rate. However, the relationships between safety culture and safety performance were more consistent and stronger when safety performance was measured at the same time than when it was measured one year after the measurement of safety culture. [74], [75] asserts that organizations with poor safety culture encourage non-compliance to safe work procedures and practices which results in safety violations because the unspoken attitudes and beliefs mean that production and commercial goals are perceived to have priority over safety.

Accident investigation reports revealed that $95 \%$ of workplace accidents were caused by unsafe employee acts [28]. Safety behaviour is influenced by organizational safety climate and safety culture [15], [65], organizational safety commitment [90], and personality factors [41]. Indeed, [54] emphasized the importance of organizational influence on 
individual behaviour in high-risk industries because humanrelated accidents take place in an organizational context. The rice farm workers in this study all belonged to cooperatives and public irrigation schemes and work as individuals as well as cooperative. For that matter, the safety cultures that prevail at the various irrigation schemes have implications regarding their safety behaviour and safety performance.

In high risk industries, safety compliance is a high priority [67]. This represents or requires that workers follow laid down rules and regulations, wear protective clothing and equipment, avoid risky acts, etc. A number of studies in safety science research observed that safety compliance is generally higher among workers than safety participation [65], [67], [88]. Safety compliance requires that workers adhere to safety rules, while safety participation is more of discretionary acts by employees regarding safety. Safety participation has the propensity to boost the safety consciousness of the workforce. Reference [15] argued that the two dimensions of safety behaviour are important for good safety performance, and this has been demonstrated in the literature.

A number of studies explored the role of organizational factors on safety behaviour in various settings and concluded that organizational factors have great influence on workplace safety behaviour. Safety-related behaviour has been found to be a key element in accident prevention because it has direct relationship with safety performance and so deserves close attention [22]. Accident is nearly always associated with disturbance or a breakdown in existing cultural convictions and norms related to risk [71]. This suggests that the nature of safety related values, norms and attitudes would have implications for safety behaviour on the job, which in turn would affect safety outcomes. The present study therefore hypothesized that safety behaviour as a composite would relate negatively with safety performance. Also, the farm workers were expected to exhibit higher safety compliance than safety participation, with safety compliance relating stronger to safety performance than safety participation.

\section{Safety Culture, Safety Behaviour and Safety Performance}

Conclusions from the Chernobyl accident investigation and subsequent research findings brought to the fore that the quality of safety culture at a work place has a causal relationship with the safety-related behaviour of employees [57], [89]. Literature indicates that there is a link between safety culture and safety behaviour, and safety performance [30], [31], [64], [79]. The safety culture of an organization shapes the beliefs, values, and behaviours of the workforce regarding safety because "it creates advantages or disadvantages based on the message it gives to group members" [38], p. 27. Safety culture, as a sub-facet of organizational culture, is said to have influence on the attitudes and behaviours of workers in organization in relation to their health and safety behaviour or safety performance. The prevailing health and safety culture within an organization has great effect on the health and safety related behaviour of the workforce [35]. He noted further that the development of a positive safety culture is very important if high standards of health and safety are to be achieved and maintained.

In a cross-sectional survey, [17] found a positive safety climate has a positive effect on both components of safety behaviour of employee (safety compliance and participation). Thus, consistently, safety culture or climate has been found to be very important in the safety behaviour of workers. The nature of safety climate determines what employees do regarding health and safety. In support of the positive effect of safety culture on safety behaviour [21] indicated that team safety climate influenced proactive behaviours by increasing proactive orientation but influenced prosocial behaviours by increasing affective commitment. In a cross-sectional survey among multinational gold mining companies in Ghana investigating the influence of safety climate on safety performance, [45] found that safety climate had a positive relationship with safety performance. Meanwhile, the work of [45] actually measured safety performance with the two component safety behaviour of safety compliance and safety participation (i.e. safety behaviour in this paper).

Perceived safety climate was found to be an antecedent to have a significant and positive influence on organizational safety performance [87]. Again, [66] found safety culture to have positively influenced safety behaviour of workers because safety culture acts as a frame of reference that provides clues about the ultimate importance of safety at their workplace. In a study of railway workers in the US, [50] also had a result supporting that safety culture is positively and significantly related to safety performance, such that with a matured safety culture, safety performance was improved. Further, [89] agreed with this assertion, and added that it is within the frame of reference that employees receive, interpret and make sense of signals from a complex net of different sources (e.g. colleagues, policies, rules, practices) about expected behaviours that are supported and rewarded.

In summary, the literature indicated that safety culture has both direct and indirect link with safety performance, and a positive safety culture has been found to have promoted safety performance in all forms of organizations.

\section{E. Safety behaviour as a mediator of the relationship between safety culture and safety performance}

Safety culture has been found to be a predictor of accidents in several studies as indicated above e.g. [90]. However, [66] postulates that the relationship between safety culture and safety performance (e.g. accidents) is mediated by safety behaviour. Thus, safety culture directly determines how people behave regarding safety, and those behaviours have consequences on safety performance. Neal and Griffin argued that if both safety culture and safety behaviour are in the model the effect of safety behaviour should be expected to be stronger than the effects of safety culture on safety performance. In their 2006 study that spans over a five-year period, focusing on the causal chain linking safety climate to safety performance, through safety behaviour, Neal and Griffin found both safety culture and safety behaviours to be significant predictors of safety performance in one year, but safety climate did not predict accident rates in the following year. They explained that this is due to the fact that safety climate is a distal predictor of 
safety performance, whereas safety behaviour is a more proximal predictor. Thus, safety culture has a stronger link with safety behaviour than with safety performance, and safety behaviour tends to be the immediate determinant of safety performance. In this study, safety behaviour has accordingly been postulated to mediate the relationship between safety culture and safety performance.

\section{F. Hypotheses}

1. Safety culture will predict (a) safety behaviour and (b) safety performance of rice farm workers.

2. Safety behaviour will predict safety performance of rice farm workers

3. Safety participation of rice farmers will predict their safety performance more than their safety compliance.

4. Safety behaviour will mediate the effect of safety culture on safety performance.

\section{METHODS}

\section{A. Research Design}

The design for the study was the cross-sectional survey, using structured questionnaires to collect the data. According to [78] the term survey mostly represents a process of collecting information from a section of individuals. The basic idea of a survey is to measure variables by asking questions and examining the relationships among the measures [80]. They observed that the most commonly used survey design is the crosssectional design. A cross-sectional survey involves data collection at a particular point in time from a sample drawn from a specific population [80]. A cross-sectional survey is a snapshots of the populations about which data is collected to make inferences about the population of interest at one point in time [33]. It examines the relationship between variables of interest as they exist in a defined population at a single point in time or over a short period of time.

This study employed the cross-sectional survey because questionnaire was used to elicit responses from a cross section of rice farmers of diverse demographic background, drawn from three different rice irrigation schemes. The study obtained data from a large representative sample of rice farm workers at one point in time to obtain a snapshot of the health and safety situation of rice farm workers in southern Ghana.

\section{B. Study Setting and Population}

The study was conducted in Southern Ghana with major rice Irrigation Schemes. The irrigation schemes had structured systems of operation, headed by Scheme Managers. The scheme managers are assisted by extension officers and help in the supervision of the operations of the farmers. The farmers also organized themselves into Cooperatives, with executives that manage the affairs of the Co-operatives. The scheme managers, with their supporting staff, together with the leaders of the Co-operatives provide support to the farmers in various ways. Thus, the schemes have a semblance of structures in corporate organizations.

The accessible or study population consisted of rice farm workers and scheme managers of three major rice irrigation schemes the Greater Accra and Central Regions of Ghana.
The number of workers as obtained from the scheme managers formed the basis for the sampling. The total workforce for the three schemes was 2938, made up of 1973 females and 965 females.

\section{Sample and Sampling Procedure}

The sampling procedures adopted were simple random and consecutive sampling. The power estimate of a-priori sample size determination procedure was used to establish the adequacy of the sample used. Given the number of observed and latent variables in the model, the anticipated effect size, and the desired probability and statistical power level, the appropriate sample size was determined. The recommended sample size for this paper that used the Partial Least Square structural equation model (PLS-SEM), was 137 [82]. A total of 537 respondents were however sampled from the three irrigation schemes, but the final sample used for the analysis, as a result of a few non-response, incomplete questionnaires and bad data was 469.

Responses from a total of 469 rice farmers ( 347 males and 122 females) sampled from the three irrigation schemes meet the quality criteria for the study. Males dominated the sample because of the nature of rice farming. The ages of the rice farmers ranged from 23 years to 80 years, with mean age of 45.96 years. Years of rice farming experience also ranged between 1 year and 45 years, with average of 13.65 years.

TABLE I: EDUCATIONAL LEVEL DISTRIBUTIONS OF RESPONDENTS

\begin{tabular}{lcc}
\hline Educational Levels & Freq & Percent \\
\hline No formal education & 113 & 24.1 \\
\hline Basic (Primary/ JSS/ Middle) School & 242 & 51.6 \\
\hline Secondary (SSSCE/ WASSE) & 88 & 18.8 \\
\hline Tertiary (HND/First Degree equivalent) & 26 & 5.5 \\
\hline Total & 469 & 100.0 \\
\hline
\end{tabular}

Most of the farmers attained basic level of education, with only $55 \%$ having attained tertiary level of education. Thus, about $75.9 \%$ of the rice farmers obtained at least basic level of education.

\section{Research Instrument}

Structured questionnaires were the main instrument for the quantitative study. Given that some of the rice farmers could not read or understand the English Language, two versions of the set of questionnaires were used: English version and a translated Twi version. The Questionnaire was translated from English to Twi by the Department of Linguistics and Ghanaian Languages at the University of Cape Coast. Though a few of the non-educated respondents were of different ethnic background, everyone could understand and speak the Twi, which is a common Language in Ghana. As suggested by [8], semantic equivalence was achieved through the use of two independent forward translators who were professional translators of English to Twi documents at the Department of Ghanaian Languages at the University of Cape Coast. Given that all the respondents were Ghanaians working in the same rice irrigation schemes, the issues of normative and conceptual equivalence were not challenges. In addition to 
semantic, normative and conceptual equivalence, the measurement invariance of composite model (MICOM) procedure [39] proposed was used to assess the compositional equivalence and equality of mean composite score and variances of the measures between the two language respondents. The results showed that there was full measurement invariance between the Twi and the English language respondents. Consequently, the two were put together for all subsequent analyses.

During the evaluation of the measurement model, a few of the items in some of the scales did not load adequately and were eliminated from the analyses to improve the structural model and the prediction.

\section{Safety behaviour measures}

Safety behaviour of the rice farmers was measured with a 12-item Likert type of scale by [77]. There are six items each for the two components of safety behaviour: safety participation and safety compliance. The instrument was adapted to suit the rice farms conditions and pilot-tested before use. It is scored on a five point agree (5) - disagree (1) scale. This means that the score range for each subcomponent is from 6 to 30, and the overall composite score for safety behaviour ranges from 12 to 60 . Higher score indicates better safety behaviour.

For the current study, five of the items did not load adequately and were omitted from the analysis. This improved the reliability and the AVE of the scale, and ultimately the structural model. The reliability coefficients obtained for the present study were 0.897 and 0.919 for Cronbach's alpha and composite reliability respective, with an AVE of .842 (see Table II). Reported reliabilities range from 0.76 and above and from the pilot testing reliability coefficients of $0.87,0.74$ and 0.80 for the composite, safety participation and safety compliance respectively were obtained.

\section{Safety performance measure}

Safety performance was measured with adapted form of the incident reporting rate questionnaire [6] which consists of three components, namely, physical symptoms, psychological symptoms and accident rates of respondents. The original scale is made up of 27 incidents, but the adapted version for this study has 39 incidents and respondents are asked: "In the last month, how frequently did you experience these on the job?" The scale is scored on a 5-point Likert scale from 1 (never) to 5 (more than 5 times).

This questionnaire has been used widely and has reported high internal reliability alpha ranging from 0.70 to 0.80 , and also found to have good validity [63], [47]. In the pilot test, the internal reliability coefficients for the questionnaire and its components (physical symptoms, psychological symptoms and accident) were respectively calculated .64, 0.76 and 0.60 , with the overall scale alpha coefficient of 0.83 . This suggests that the safety performance scale and its subscales have acceptable internal consistency. The psychometric properties for the current paper are present in Table II.
TABLE II: Evaluation Of THE LOADINGS OF SUB-SCALES ON THEIR LATENT CONSTRUCTS

\begin{tabular}{|c|c|c|c|c|c|}
\hline Paths & Original & Mean & $\mathrm{Sd}$ & t-stats & $\begin{array}{c}\text { p- } \\
\text { value }\end{array}$ \\
\hline Safety Culture & \multicolumn{5}{|c|}{$\mathrm{CA}=0.952 \mathrm{CR}=0.956 \mathrm{AVE}=0.676$} \\
\hline SCTR->GRPN & 0.832 & 0.832 & 0.019 & 43.788 & 0.000 \\
\hline SCT->MGTC & 0.823 & 0.823 & 0.015 & 55.405 & 0.000 \\
\hline SCTR->MGTPR & 0.770 & 0.768 & 0.023 & 33.396 & 0.000 \\
\hline SCTR->SFTCOM & 0.862 & 0.862 & 0.012 & 72.716 & 0.000 \\
\hline SCTR->SFTPT & 0.810 & 0.811 & 0.017 & 48.149 & 0.000 \\
\hline SCTR->SFTRPT & 0.865 & 0.866 & 0.012 & 73.527 & 0.000 \\
\hline SCTR->SFTTRN & 0.813 & 0.815 & 0.021 & 39.242 & 0.000 \\
\hline \multicolumn{6}{|c|}{ Safety Behaviour $\quad \mathrm{CA}=0.897 \mathrm{CR}=0.919 \mathrm{AVE}=0.842$} \\
\hline SBVR -> SCB & 0.938 & 0.938 & 0.007 & 125.595 & 0.000 \\
\hline SBVR -> SPB & 0.922 & 0.922 & 0.009 & 105.810 & 0.000 \\
\hline \multicolumn{6}{|c|}{ Safety Performance ${ }_{\mathrm{CA}}=0.907 \mathrm{CR}=0.917 \mathrm{AVE}=0.708$} \\
\hline $\mathrm{SPF}->\mathrm{ACC}$ & 0.883 & 0.886 & 0.012 & 74.938 & 0.000 \\
\hline SPF->PHY & 0.933 & 0.937 & 0.008 & 115.626 & 0.000 \\
\hline SPF->PSYC & 0.756 & 0.759 & 0.019 & 39.773 & 0.000 \\
\hline
\end{tabular}

$\mathrm{CA}=$ Cronbach's alpha; $\mathrm{CR}=$ Composite reliability; $\mathrm{AVE}=$ Average variance extracted.

\section{Safety culture measure}

The safety culture scale used by [43] was adapted. This scale was based on [23] and [34] psychosocial safety culture scale. The original scale is made up of five dimensions with three items for each: Management priority for physical health and safety, management commitment to physical health and safety, group norms and behaviour related to physical health and safety, safety Communication, and participation and involvement. Two other components considered to be very relevant for this study and found to be common dimensions used in literature, safety training and safety reporting systems were added because of their relevance to the current study. The two components consist of 9 items. The total items for the safety culture scales used for this study therefore were 24 . The items were scored on a five-point likert scale, ranging from never (1), rarely (2), sometimes (3), mostly (4), and always (5). Scores were added across items to obtain scale and subscale measures of safety culture. The overall safety culture score ranges from 24 to 120 , with higher scores representing better safety culture.

The scale has good reported psychometric properties. For instance, [12] reported Cronbach's alphas for the five factors in their study as: 0.87 (top management priority), 0.89 (direct management commitment), 0.90 (group norms and behaviour), 0.91 (safety communication), and 0.86 (involvement and participation). The alpha coefficient obtained in the pilot testing are $0.78,0.65,0.77,0.82,0.71$, 0.64 and 0.74 for the combined scale, top management priority, direct management commitment, group norms and behaviour, involvement and participation, safety training, and safety reporting respectively. The coefficient for safety communication however, was not good enough, but the scale was included in the study. Table presents the Cronbach's alpha, composite reliability, and average variance extracted for the scales, together with the loadings 
of the subscales obtained in the main study. All the scales demonstrated good reliability and validity for the Ghanaian rice farm workers.

\section{E. Evaluation of the Structural Model Procedure}

The structural model tests the causal relationships between the exogenous latent variables and the endogenous latent variables [26]. The significance of the path coefficients is determined through the PLS bootstrapping approach. The goodness of fit of the structural model was established by the coefficient of determination (R2) which explains the variance in the endogenous variable that is explained by the endogenous variable [26]. This represents the overall fit of the structural model [36], [40]. The predictive relevance (Q2) and the effect size (f2) are also used to establish the fitness of the analytical model. Predictive relevance is established by the value of StoneGeisser Q2. Stone-Geisser Q2 greater zero (0) is indicative of predictive relevance of the model. According to [18], a Q2 of 0.02 is considered to be a small effect size, 0.15 , medium and 0.35 considered high effect size.

\section{F. Mediation Analysis Procedure}

The bootstrapping approach by [73] and [72] was used to test the significance of the mediation effects in this study. This approach is a non-parametric inferential technique that randomly draws several samples with replacement from the original data set. This approach does not require assumptions about the shape of the variable distribution and is considered the best approach to test mediation effect since the distribution of the indirect effect has been found to be asymmetrical [69]. Bootstrapping helps to determine the significance of the mediation effect [32]. Mediation effect always exists when the indirect effect is significant, and there is no mediation if the indirect effect is not significant [26], [36].

To evaluate the strength, one approach is to partition the total, direct and indirect effects and to calculate the VAF which involves the estimation of the indirect-to-direct effect ratio. This ratio explains the extent to which the mediation process explains the variance in the endogenous variable. Thus, the indirect effect of the exogenous variable on the endogenous variable must be tested and the strength of the indirect effect would determine the size of the mediation. The bootstrapping was again used to determine the significance of the indirect effect before the VAF ratio is computed. The VAF is computed with the simple formula:

$$
\mathrm{VAF}=\frac{\text { Indirect } \text { effect }}{\text { Total } \text { effect }}
$$

As a rule of thumb, if the VAF is less than .20 , there is nearly zero mediation, VAF between .20 and .80 indicates a typical partial mediation (Hair et. al., 2016), and VAF greater than .80 indicates full mediation.

\section{RESULTS}

\section{A. Descriptive Statistics}

The mean scores, the number of items on each scale, the scoring, as well as the minimum and maximum possible scores on the scales are presented in Table III.

TABLE III: DESCRIPTIVE STATISTICS OF SUBSCALES AND COMPOSITE SCORES Of LATENT VARIABLES (COMPOSITE SCORES OF SUB-SCALES ARE IN BOLD PRINT*)

\begin{tabular}{|c|c|c|c|c|c|c|c|c|c|c|}
\hline Variables & Mean & No of Items & Rating & Min & $\operatorname{Max}$ & Stdv. & Skewness & SE & Kurtosis & SE \\
\hline Safety participation & 13.99 & 4 & 5-Point & 4 & 20 & 3.88 & -0.659 & 0.113 & 0.064 & 0.225 \\
\hline Safety compliance & 11.49 & 3 & 5-Point & 3 & 15 & 2.49 & -0.250 & 0.113 & -0.715 & 0.225 \\
\hline Safety behaviour* & 25.48 & 7 & 5-Point & 7 & 35 & 5.82 & -0.582 & 0.113 & -0.029 & 0.225 \\
\hline Mgt safety priority & 10.63 & 3 & 5-Point & 3 & 15 & 2.98 & -0.591 & 0.113 & -0.619 & 0.225 \\
\hline Mgt commit to safety & 10.11 & 3 & 5-Point & 3 & 15 & 2.87 & -0.191 & 0.113 & -0.581 & 0.225 \\
\hline Group safety norms & 10.08 & 3 & 5-Point & 3 & 15 & 3.29 & -0.641 & 0.113 & -0.072 & 0.225 \\
\hline Safety communication & 9.94 & 3 & 5-Point & 3 & 15 & 2.51 & -0.706 & 0.113 & 0.362 & 0.225 \\
\hline Safety participation & 10.03 & 3 & 5-Point & 3 & 15 & 2.75 & -0.686 & 0.113 & 0.222 & 0.225 \\
\hline Safety reporting & 10.00 & 3 & 5-Point & 3 & 15 & 2.97 & -.295 & 0.113 & -0.586 & 0.225 \\
\hline Safety training & 15.88 & 5 & 5-Point & 5 & 25 & 5.83 & -.288 & 0.113 & -0.867 & 0.225 \\
\hline Safety culture* & 76.68 & 23 & 5-Point & 23 & 115 & 19.19 & -.456 & 0.113 & -0.509 & 0.225 \\
\hline Physical symptoms & 40.76 & 20 & 5-Point & 20 & 100 & 9.89 & .599 & 0.113 & 0.234 & 0.225 \\
\hline Psych symptoms & 10.19 & 5 & 5-Point & 5 & 25 & 4.58 & 1.214 & 0.113 & 1.475 & 0.225 \\
\hline Accidents & 14.76 & 9 & 5-Point & 9 & 45 & 4.60 & 1.327 & 0.113 & 2.660 & 0.225 \\
\hline Safety performance* & 65.70 & 34 & 5-Point & 34 & 170 & 16.34 & 0.582 & 0.113 & 0.148 & 0.225 \\
\hline
\end{tabular}

*Represents composite (overall) scores.

The results indicated that the overall safety behaviour of the rice farmers was quite good, which reflected in the subscales as well. Thus, generally, the safety behaviour of the rice farmers seems to be quite good, but there is more room for improvement. The overall safety culture score of

the rice farmers was also quite satisfactory, and this reflected in all the dimensions as well. Finally, safety performance scores were also quite high indicating poor safety performance. Higher scores represent more health and safety incidents and low score means low levels of health 
and safety incidents and issues. The overall safety performance score quite high, considering the health and safety of workers must not be compromised at any point.

Considering the normality of the distribution of the scores, the skewness and kurtosis statistics indicate that the distributions of all composite latent variables were largely normal. Skewness and kurtosis values between -2 to +2 [83] are considered acceptable. The normality or otherwise of the data was not a challenge because PLS-SEM is a nonparametric analytical approach which does not have strong requirements regarding normality of the data.

The resulted indicated that the model was significant and safety culture and safety behaviour together accounted for $43.8 \%$ of the variance in safety performance with predictive relevance $\left(\mathrm{Q}^{2}\right)$ of 0.084 .
The first hypothesis postulated that: Safety culture of will predict the (a) safety behaviour and (b) safety performance of rice farmers. The result (Table IV) showed that the effects of safety culture (SCTR) on both safety behaviour $(\beta=0.487, \quad p<0.001)$ and safety performance $(\beta=0-.466$, $\mathrm{p}<0.001)$ were both significant. The effect size $\left(\mathrm{f}^{2}\right)$ for the effect of safety culture on safety behaviour $\left(f^{2}=0.362\right)$ was large, and that of safety culture and safety performance $\left(\mathrm{f}^{2}=0.248\right)$ was moderated, per Cohen's criteria. This means that hypotheses 1(a) and 1(b) were both supported. The results show that positive safety culture could improve the safety behaviour of the rice farmers and reduce their health and safety concerns.

TABLE IV: RESUlTS OF STRUCTURAL MODEL

\begin{tabular}{|c|c|c|c|c|c|c|c|}
\hline \multirow[b]{2}{*}{ Paths } & \multicolumn{3}{|c|}{ Standardized coefficients $(\beta)$} & \multirow[t]{2}{*}{ VAF } & \multirow{2}{*}{$\begin{array}{c}\text { Effect Size } \\
f^{2}\end{array}$} & \multicolumn{2}{|c|}{ Quality Criteria } \\
\hline & Direct & Indirect & Total & & & $R^{2}$ & $Q^{2}$ \\
\hline SBVR $->$ SPF & $0.161^{* *}$ & & $0.161^{* *}$ & & 0.029 & $0.438^{* * * * *}$ & 0.084 \\
\hline SCTR -> SBVR ->SPF & $-0.466^{* * * *}$ & $0.078^{* *}$ & $-0.388^{* * * *}$ & -0.201 & $0.248^{* * * *}$ & & \\
\hline SCTR -> SBVR & $0.487^{* * * *}$ & & $0.487^{* * * *}$ & & $0.362^{* * * *}$ & & \\
\hline
\end{tabular}

$* p<0.05 ; * * p<0.01 ; * * * p<0.005 ; * * * * p<0.001$

$S B V R=$ Safety behaviour; $S C T R=$ Safety culture; SPF = Safety performance

Hypothesis 2 also postulated the effect of safety behaviour on safety performance of rice farm workers. The result showed a significant positive effect of safety behaviour on safety performance $(\beta=0.161, \mathrm{p}<0.01)$, with a small effect size $\left(\mathrm{f}^{2}=0.029\right)$. This implies farm workers who reported higher safety behaviour and reported more health and safety challenges. Even though the relationship was significant, it was not in the expected relationship. Further analysis had to done by partitioning safety behaviour into its components of safety compliance and safety participation.

\section{B. Safety Behaviour dimensions and safety performance}

Hypothesis 3 postulated safety participation would be a stronger predictor of the rice farmers' safety performance than their safety compliance. The results, as presented in Table $\mathrm{V}$ indicated that safety compliance had negative associations with all the dimensions of safety performance. Safety participation however, had positive relationship with all the dimensions of safety performance. Meanwhile, not all the relationships were significant. Safety compliance had significant negative relationship with only with psychological symptoms dimension of safety performance $(\beta=-0.311, p<0.001)$, with a small effect size. Safety participation on the other hand had a significant positive effect on physical symptoms dimension of safety performance $(\beta=0.479, p<0.001)$, with moderate effect size.

Thus, the two dimensions of safety behaviour had different effects on safety performance, and their cumulative effect resulted in the positive relationship mentioned above in hypothesis 2 . The positive effect of safety participation was stronger than the negative effect of safety compliance. Hypothesis 3 was therefore supported by the results, yet negative effects were expected from both dimensions of safety behaviour.

\begin{tabular}{ccccccccc}
\multicolumn{7}{c}{ TABLE V: PATH COEFFICIENTS OF SAFETY BEHAVIOUR DIMENSIONS ON SAFETY PERFORMANCE } \\
\hline Model & $(\mathbf{O})$ & $(\mathbf{M})$ & STD & T Stats & P Values & f-Sq & $\mathbf{R}^{\mathbf{2}}$ & $\mathbf{Q}^{2}$ \\
\hline SCB -> ACC & -0.228 & -0.231 & 0.144 & 1.587 & 0.056 & 0.026 & \multirow{2}{*}{0.041} & 0.009 \\
SPB -> ACC & 0.293 & 0.261 & 0.217 & 1.349 & 0.089 & 0.042 & & \\
SCB -> PHY & -0.168 & -0.144 & 0.185 & 0.911 & 0.181 & 0.016 & \multirow{2}{*}{0.141} & 0.013 \\
SPB -> PHY & $0.479^{* * * *}$ & 0.469 & 0.118 & 4.069 & 0.000 & 0.126 & & \\
SCB -> PSYC & $-0.311^{* * * *}$ & -0.314 & 0.067 & 4.617 & 0.000 & 0.049 & & \multirow{2}{*}{0.073} \\
SPB -> PSYC & 0.061 & 0.059 & 0.078 & 0.780 & 0.218 & 0.002 & & \\
\hline
\end{tabular}

$* p<.05 ; * * p<.01 ; * * * p<.005 ; * * * * p<.001$.

$S C B=$ Safety compliance behaviour $; S P B=$ Safety participation behaviour, ACC = Accidents; PSYC = Psychological symptoms; PHY = Physical symptoms.

\section{Mediation effects of safety behaviour}

Hypothesis 4 proposed mediation effect of safety behaviour on the effects of safety culture on safety performance. The results (Table IV) indicated that the indirect effect of safety culture on safety performance $(\beta=0.078, p<0.01)$ was significant, with a moderate variance accounted for $(\mathrm{VAF}=-0.403)$. This is a competitive partial mediating effect of safety behaviour on the relationship between safety culture and safety performance. The results 
suggest that compliance to laid down safety rules and procedures of work helps to reduce psychological health and safety challenges, but not significant in predicting physical and accidents of the rice farmers. This is a contrary to expectation and requires further exploration.

\section{DISCUSSION OF FINDINGS}

\section{A. Effects of Safety Behaviour on Safety Performance}

The paper expected safety behaviour to have a negative relationship with safety performance of the rice farm workers. Thus, higher score on safety behaviour was expected to be related with lower report of health and safety challenges and accidents. The results however show that safety behaviour rather had a positive relationship with safety performance. This result contradicts expectation and most of the empirical data, suggesting that positive safety behaviour was related to increased health and safety challenges (poor safety performance), such as accidents, physical health and psychological health symptoms.

A number of studies reported that safety behaviour is an immediate or most proximal antecedent of safety performance [20], [66], and has a negative relationship with safety performance. Researchers such as [25], [50], [61], [86], all reported negative relationships between safety behaviour and safety performance. Safety behaviour was expected to have a negative relationship with safety performance (health and safety challenges), but that was not the case in this study. Unsafe acts or behaviours logically and empirically ought to be of concern regarding causal factor in workplace accident/injures [27].

A number of studies [17], [16] indicate that the two components of safety behaviour are associated with workrelated accidents and injuries (safety performance). The current finding in this paper that safety compliance had negative associations with all the dimensions of safety performance (accidents, physical symptoms and psychological symptoms), whereas safety participation had positive association with all the dimensions of safety performance confirms the proposition of differential association. The positive effects of safety participation were stronger than the negative effects of safety compliance and this led to the overall weak positive relationship of safety behaviour and safety performance.

It is important to note that, mere compliance with safety procedures is not sufficient, but safety participation is important in reducing overall safety incidents [67] and [50]. When workers do not participate in activities that enhance safety at the workplace, negligent behaviours of some workers may create conditions that could harm other on the job [65]. In the current study, it seems that the farmers who engage in safety participation behaviour had to go the extra mile to put things right. This might have accounted for their increased physical health symptoms.

The conclusion from the findings of the present study is that safety compliance is essential in the management of safety among the rice farmers. However, the findings regarding safety participation behaviour require further investigation. Further studies might be needed in this area to find out why safety participation related positively with safety performance of the farm workers.

\section{B. Safety culture, safety behaviour and safety performance}

Occupational culture of safety is very essential for the wellbeing and productivity of any organization, irrespective of the sector of the economy that it operates. Prioritizing the beliefs, assumptions, values and actions that ensure safe and healthy work make an organization have a culture of safety which has enormous implications for safety behaviour and outcomes.

The present study found safety culture to be a significant direct positive predictor of safety behaviour, and significant direct negative predictor of safety performance. This means that having a positive safety culture at the workplace would make employees engage in behaviours that would enhance safety at the workplace. This result is in line with findings in the industrial settings which have established that safety culture and safety behaviour are strongly related [30], [31], [64] and [79]. The reason for this positive relationship is that safety behaviour serves as a frame of reference that guides employees regarding acceptable behaviours at the workplace in various contexts [89].

Extant literature of meta-analytic studies e.g. [9], [14], [15] should that the effect of safety culture on safety performance is negative and mostly ranges between -0.22 to -0.39 , while that of safety culture on safety behaviours is positive and ranges from 0.43 to 0.61 . The findings in the present study in consistent with these reports in the literature.

The prevailing safety culture of an organization provides contextual cues that the employee uses to decide whether to behave in a safe or unsafe manner at work. Thus, the positive relationship between safety culture and safety behaviour among the rice farmers was in consonance with the literature in the industrial setting. Positive safety climate enhances safety behaviour among employees, consequently improving safety performance [91] because the prevailing culture primes employees concerning what they should do when faced with safety challenges. Research in safety culture is of great importance to contemporary researchers because organisational accidents occur within a cultural and social context [76]. When workers continuously discharge their duties without following safety regulations and procedures it results in the creation of a negative safety culture [1], [4].

\section{Mediating Effect of Safety Behaviour on the Effect of Safety Culture on Safety Performance}

In the present study, safety behaviour had a competitive partial mediation effect on the relationship between safety culture and safety performance. Complementary mediation effect was expected rather than the competitive effect obtained in the current study. The relationship between safety culture and occupational accidents is mediated by safety behaviour [67]. Given that safety culture has been found consistently to relate positively with safety behaviour and positive safety behaviour in turn reduces health and safety incidents, a mediation relationship between safety culture and safety performance was postulated and tested in this study. Thus, safety culture directly determines how people behave regarding safety, and those behaviours have 
consequences on safety performance. Neal and Griffin stressed their argument further by suggesting that if both safety culture and safety behaviour are in the model, the effect of safety behaviour would be expected to be stronger than the effects of safety culture on safety performance. The results of this present study did not support Neal and Griffin's stance. The direct effect of safety culture in this study was stronger than that of safety behaviour. In addition, the effect of safety behaviour was positive, contrary to expectation. This means the situation in the formal and industrial sector may be different from that of the informal agricultural sector. Further studies may be required to fully explore this.

\section{CONCLUSIONS, IMPLICATIONS AND RECOMMENDATIONS}

We conclude from the findings in the present study that occupational safety plays a crucial role in enhancing the safety behaviour as well as safety performance at the workplace. Similar to what pertains in the formal and industrial settings, the findings here indicate that safety culture has similar implication in the promotion of health and safety in the informal agricultural sector. However, the role of safety behaviour seems to be different in the informal sector. We recommend further studies in the informal agricultural sector to have a better understanding of the role of safety behaviour safety promotion. It could also be concluded that one of the important mechanism through which safety culture influences safety performance is safety behaviour.

The findings in the present study imply that researchers, practitioners and workers alike have to ensure that integrative and pragmatic measures are put in place to promote safety culture and safety behaviour, as these have enormous implication for health, safety and wellbeing at work in all sectors. As the socio-cultural sub-systems theory espouses, the sub-cultures and working systems at any workplace need to harness resources and efforts to promote positive safety culture at work. Whichever culture is reinforced, directly or indirectly, has implications for the health and well-being of the workforce.

There is also the need for further rigorous research to explore the critical antecedents of safety performance. Factors such as risk perception, hazards assessment, personal safety values, motivation, beliefs, etc could be explored to have a comprehensive appreciation of workplace safety and health.

A critical component of safety culture is management commitment to the promotion of safety. We recommend that management should prioritize safety and wellbeing of their workers. Necessary policies, training, personal protective equipment must be provided to all workers. Also, enforcement of safety regulations and policies must not be compromised and relegated at the expense of productivity, for health and safety of workers and all is fundamental human right. Also, safe work is ultimately decent work.

\section{ETHICAL CONSIDERATIONS AND APPROVAL}

There were no inherent or known risks to the respondents, nor were there any costs for participating in the study.
Anonymity and confidentiality of respondents and information obtained from there were ensured. Information obtained were reported in aggregate without individual identification. Respondents were free to withdraw from the study at any point, or refrain from answer a particular question or group of questions without any cost to them. The study protocol was approved by the Ethics Committee for Humanities (ECH 072/15-16) of the University of Ghana, Legon.

\section{LimitATIONS OF THE STUDY}

The data for the present paper was collected from rice farm worker in major rice irrigation schemes in southern Ghana. For this reason, the findings of this study must be to the formal and other informal sectors with caution, as safety in rice farm may differ from other sectors.

This notwithstanding, the present paper contributed to the literature by applying safety culture investigation in informal agriculture. The paper has broadened the scope of safety science research in the informal sector, and to a population that has been neglected in safety culture and safety performance research.

\section{REFERENCES}

[1] J. L. Agnew, and A.C. Daniels, "Safe by accident? Take the luck out of safety: Leadership practices that build a sustainable safety culture," Atlanta, GA: Performance Management Publications, 2010.

[2] L. Alfers, "Occupational Health and Safety for Market and Street Traders in Accra and Takoradi, Ghana”. 2009, Retrieved on March 9, 2015 from www.wiego.org.

[3] A. K. Apekey, "Traditional values and management in Ghana" (PhD thesis), University of Ghana, Legon, Ghana, 2001.

[4] A. Arboleda, P. C. Morrow, M. R. Crum, I. Shelley, and C. Mack, "Management practices as antecedents of safety culture within the trucking industry: Similarities and differences by hierarchical level," Journal of Safety Research, vol. 34, pp. 189-197, 2003.

[5] J. Y. Avotri, and V. Walters, "You just look at our work and see if you have any freedom on earth: Ghanaian women's accounts of their work and their health," Social Science and Medicine, vol. 48, no. 9, pp. 1123-1133, 1999.

[6] J. Barling, C. Loughlin, and E. K. Kelloway, "Development and test of a model linking safety-specific transformational leadership and occupational safety," Journal of Applied Psychology, vol. 87, pp. 488-96, 2002.

[7] D. Beaton, C. Bombardier, F. Guillemin and M.B. Marcos Bosi Ferraz, "Recommendations for the cross-cultural adaptation of the DASH and Quick DASH outcome Measures," Spine: Institute for Work \& Health, 2007.

[8] D. Beaton, C. Bombardier, F. Guillemin and M.B. Ferraz, "Recommendations for the cross-cultural adaptation of health status measures," New York: American Academy of Orthopaedic Surgeons, vol. 12, pp. 1-9, 2002.

[9] J. M. Beus, S.C. Payne, M.E. Bergman and W. Arthur Jr,"Safety climate and injuries: an examination of theoretical and empirical relationships," Journal of applied psychology, vol. 95, no. 4, pp. 713, 2010.

[10] W.C. Borman and S.J. Motowidlo, "Expanding the criterion domain to include elements of contextual performance," In N. Schmitt and W. C. Borman (Eds.), Personnel selection in organizations, San Francisco: Jossey-Bass, pp. 71-98, 1993.

[11] M. Bosompem and E. Mensah, "Occupational hazards among cocoa farmers in the Birim South District in the Eastern Region of Ghana," ARPN Journal of Agricultural and Biological Science, vol. 7, no.12, pp. 1055- 1061, 2012.

[12] A. W. Bronkhorst, "The cocktail-party problem revisited: Early processing and selection of multi-talker speech," Attention, Perception, \& Psychophysics, vol. 77, no.5, pp. 1465-1487, 2015.

[13] M. J. Burke, R.O Salvador, K. Smith-Crowe, S. Chan-Serafin, A Smith, A. and S. Sonesh, "The dread factor: How hazards and safety 
training influence learning and performance," Journal of Applied Psychology, vol. 96, no.1, pp.46-70, 2011.

[14] M.S. Christian, J.C. Bradley, J.C. Wallace and M.J. Burke, "Workplace safety: A meta-analysis of the roles of person and situation factors," Journal of Applied Psychology, vol. 94, pp.1103 1127, 2009.

[15] S. Clarke, "Contrasting perceptual, attitudinal and dispositional approaches to accident involvement in the workplace," Safety Science, vol. 44, pp.537-550, 2006

[16] S. Clarke, "Safety leadership: A meta-analytic review of transformational and transactional leadership styles as antecedents of safety behaviours," Journal of Occupational and Organisational Psychology, vol. 86, no.1, pp.22-49, 2013.

[17] S. Clarke and K. Ward, "The role of leader influence tactics and safety climate in engaging employees' safety participation", Risk Analysis, vol 26, no 5, pp. 1175-1185, 2006.

[18] J. Cohen, "Statistical power analysis for the Behavioral Sciences," (2nd ed.). Mahwah, NJ: Erlbaum, 1988.

[19] K. S. Cole, S. M. Stevens-Adams, and C. A. Wenner, "A Literature Review of Safety Culture," Sandia report, 2013, Retrieved on July 6, 2017 from www.osti.gove/bridge.

[20] M. Curcuruto, S. M. Conchie, M. G. Mariani, and F.S. Violante, "The role of prosocial and proactive safety behaviors in predicting safety performance," Safety Science, vol. 80, pp. 317-323, 2015

[21] M. Curcuruto, D. Guglielmi, and M. G. Mariani, "Organizational citizenship for safety: Psycho-social processes of mediation," Psicologia sociale, vol. 8, no. 2, pp. 229-248, 2013.

[22] S. Didla, K. Mearns, and R. Flin, "Safety citizenship behaviour: proactive approach to risk management," Journal of Risk Research, vol. 12, no. 3, pp. $475-483,2009$.

[23] M. F. Dollard, and S. Kang, "Psychosocial safety climate measure," Adelaide: Work and Stress Research Group, University of South Australia, 2007.

[24] B. Effah, K. Antwi, G. Adu, and E. Boampong, "The safety culture of artisans at the Sokoban wood village enclave, Ghana," American International Journal of Contemporary Research, vol. 3, no. 12, pp. 121-128, 2013.

[25] J. A. Erickson, "Corporate culture: The key to safety performance," Occupational Hazards, vol. 62, no. 4, pp. 45-50, 2000

[26] G. D. Garson, "Partial least squares (PLS-SEM)" (2016 ed.) Asheboro, USA: Statistical Publishing Associates, 2016, Retrieved 17 February, 2016 from www.statisticalassociates.com.

[27] T. N. Garavan, and F. O'Brien, "An investigation into the relationship between safety climate and safety behaviors in Irish organizations," Irish Journal of Management, vol. 22, pp. 141-170, 2001

[28] E. S. Geller, Actively caring for occupational safety: Extending the performance management paradigm. In C. M. Johnson \& W. K. Redmon \& T. C. Mawhinney (Eds.), Handbook of Organizational Performance: Behavior Analysis and Management: pp. 303-326. Binghamton, New York Haworth Press Inc, 2001.

[29] Ghana Statistical Service. "2010 Population and housing census: Summary report of final results”. Accra: Ghana Statistical Service, 2012.

[30] M. A. Griffin, and A. Neal, "Perceptions of safety at work: a framework for linking safety climate to safety performance, knowledge, and motivation," Journal of Occupational Health Psychology, vol. 5, no. 3, pp. 347-358, 2000.

[31] F. W. Guldenmund, "The nature of safety culture: A review of theory and research," Safety Science, vol. 34, no. 1-3), pp. 215-257, 2000

[32] N. U. Hadi, N. Abdullah, and I. Sentosa, "Making sense of mediating analysis: A marketing perspective," Review of Integrative Business and Economics Research, vol. 5, no. 2, pp. 62, 2016.

[33] J. Hall, Cross-Sectional Survey Design. In: "Encyclopaedia of Survey Research Methods", Sage Publications, Inc., 2011 pp. 173. DOI: http://dx.doi.org/10.4135/9781412963947.

[34] G.B. Hall, M. F. Dollard, and J. Coward, "Psychosocial Safety Climate: Development of the PSC-12," International Journal of Stress Management, vol.17, no. 4, pp. 353-383, 2010.

[35] D. Hay, "Workplace Safety culture assessment tool: An overview," (n.d), Retrieved February 19, 2015 from www.dmhay.co.nz.

[36] J. F. Hair, J. F., G. T. M. Jr., Hult, C. M. Ringle, and M. Sarstedt, M. "A primer on Partial Least Squares Structural Equation Modeling (PLS-SEM). Thousand Oaks, CA: SAGE Publications Ltd., 2014

[37] J. Heintz, "Employment, Poverty, and Gender in Ghana," Working Paper Series, No 92. University of Massachusetts Amherst: Political Economy Research Institute, 2005.

[38] R. L. Helmreich, and A. R. Merritt, "Culture at work in aviation and medicine: National, organizational and professional influences,' Aldershot, UK: Ashgate, 2001
[39] J. Henseler, C. M. Ringle, M. Sarstedt, "Testing measurement invariance of composites using partial least squares," Internationa Marketing Review, vol. 33, no. 3, pp. 405-431, 2016.

[40] J. Henseler, C. M. Ringle, and M. Sarstedt, "Using partial least squares path modelling in advertising research: Basic concepts and recent issues," Handbook of research on international advertising, 252,2012

[41] V. B. Hinsz, G. S. Nickell, and E. S. Park, (2007). "The role of work habits in the motivation of food safety behaviours," Journal of Experimental Psychology: Applied, vol. 13, no. 2, pp. 105, 2007.

[42] A. Hill, R. Darko, J. Seffah, R. Adanu, J. Anarfi, and R. Duda, Health of urban Ghanaian women as identified by the Women's Health Study of Accra. International Journal of Gynaecology and Obstetrics, vol. 99, pp. 150-156, 2007.

[43] M. A. Idris, M. F. Dollard, J. Coward, and C. Dormann, "Psychosocial safety climate: Conceptual distinctiveness and effect on job demands and worker psychological health," Safety Science, vol. 50, no. 1, pp. 19-28, 2012

[44] International Labour Office. "Global Employment Trends for Youth. Special issue on the impact of global economic crises on the youth," Geneva: Author, 2010.

[45] U. F. F. Ismail, M. Asumeng, and K. Nyarko, "The impact of safety climate on safety performance in a gold mining company in Ghana" International Journal of Management Excellence, vol. 5, no. 1, pp. 556-566, 2015.

[46] L. Jiang, G. Yu, Y. Li, F. \& Li, "Perceived colleagues' safety knowledge / behaviour and safety performance: Safety climate as a moderator in a multilevel study,". Accident Analysis and Prevention, vol. 42, pp. 1468 - 1476, 2010

[47] F. Kiani, H. Samavatyan, S. Pourabdian, and E. Jafari, "Predictive power of incidents reporting rate and its dimensions by job stress among workers' Isfahan Steel Company", Iranian journal of public health, vol. 40, no. 3, pp. 105, 2011

[48] A. E. Kwankye, "Worker Characteristics and Compliance to Occupational Health and Safety. A Study of Naja David Wood Industry Limited in Kumasi Metropolis, 2012.

[49] E. A. Kwankye, "Worker Characteristics and Compliance to Occupational Health and Safety: A Study of Naja David Wood Industry Limited in Kumasi Metropolis" (Doctoral dissertation) Kumasi, Kwame Nkrumah University of Science and Technology, 2012

[50] A. D. Little, "Safety culture, safety behaviour and safety performance in Railway companies," 9th World Congress Rail Research, May 22 26, 2011.

[51] C. S. Lu, and C. S. Yang, "Safety climate and safety behaviour in the passenger ferry Context", Accident Analysis and Prevention, vol. 43 , pp. $329-341,2011$.

[52] N. Luhmann, The world society as a social system. "International Journal of General Systems," vol. 8, no. 3, pp. 131-138, 1982

[53] M. G. Marmot, and R. G. Wilkinson, "Social determinants of health," (2nd ed.). Oxford: Oxford University Press, 2006.

[54] D. E. Maurino, J. Reason, N. Johnston, and R. B. Lee, "Beyond aviation human factors safety in high technology systems," Aldershot, UK: Avebury Aviation, 1995.

[55] B. McKinnon, "Ethics: Theory and contemporary issues," (4th ed.) Belmont, CA: Wadsworth/Thomson Learning, 2004

[56] M. McNeill, and D. O’Neill, “Occupational disorders in Ghanaian subsistence farmers. In Proceedings of the annual conference of the Ergonomics Society," Chartered Institute of Ergonomics and Human factors, Loughborough, UK (1-3), April, 1998.

[57] K. Mearns, S.M. Whitaker and R. Flin, "Safety climate, safety management practice and safety performance in offshore environments," Safety Science, vol. 41, no. 8, pp. 641-680, 2003.

[58] S. J. Mitchual, M. Donkoh and F. Bih, 'Awareness and willingness to utilize health and safety measures among woodworkers of a timber processing firm in Ghana," Journal of Scientific Research and Reports, pp. 178-188, 2015.

[59] V. Mock, C. Frangakis, N.E. Davidson, M.E. Ropka, M. Pickett, B. Poniatowski and G. Cohen, "Exercise manages fatigue during breas cancer treatment: A randomized controlled trial," Psycho-Oncology, vol. 14, no. 6, pp. 464-477, 2005.

[60] I. Monney, D.A. Bismark, O.M. Isaac and R. A. Kuffour, "Practices among vehicle repair artisans in an urban area in Ghana," Journal of Environment and Occupational Science, vol. 3 no. 3, pp. 147, 2014.

[61] S. L. Morrow, G. Kenneth Koves and V. E. Barnes, "Exploring the relationship between safety culture and safety performance in U.S nuclear power operations," Safety Science, vol. 69, pp. 37-47, 2014.

[62] S. Muilerman, "Occupational safety and health on Ghanaian cocoa farms," Baseline report of sustainable tree crops programme, Accra Ghana, International Institute of Tropical Agriculture (IITA), 2013. 
[63] M. R. Munteanu, "Safety attitudes in the Ontario construction," [MS thesis], University of Toronto, Canada, 2005.

[64] J. D. Nahrgang, F. P. Morgeson and D. A. Hofmann, "Safety at work: A meta-analytic investigation of the link between job demands, job resources, burnout, engagement, and safety outcomes," Journal of Applied Psychology, vol. 96, pp.71, 2011.

[65] A. Neal and M.A. Griffin, "A study of the lagged relationships among safety climate, safety motivation, safety behaviour, and accidents at the individual and group levels," Journal of Applied Psychology, vol. 91, pp. 946-953, 2006.

[66] A. Neal and M. A. Griffin, "Safety climate and safety at work," In: J. Barling and M. Frone, (Eds.), the Psychology of Workplace Safety, Washington DC, American Psychological Association, pp. 15-34, 2004.

[67] A. Neal, M. A Griffin and P.M. Hart, "The impact of organizational climate on safety climate and individual behavior," Safety Science, vol. 34, pp.99-109, 2000.

[68] K. J. Nielsen and K.L. Mikkelsen, "Predictive factors for self-reported occupational injuries at 3 manufacturing Plants," Safety Science Monitor, vol.11, pp.1-9, 2007.

[69] C. Nitzl, J.L. Roldan and G. Cepeda, "Mediation analysis in partial least squares path modelling” Industrial management \& data systems, vol. 16, no. 9, pp. 1849 - 1864. DOI: 10.1108/IMDS-07-2015-0302, 2016.

[70] R. Nobles and D. Schiff, "A story of miscarriage: law in the media," Journal of Law and Society, vol. 31, no. 2, pp. 221-244, 2004.

[71] N. Pidgeon, "Safety culture: Transferring theory and evidence from the major hazards industries," Paper presented at the Behavioural Research in Road Safety 10th Seminar, 2001.

[72] K. J. Preacher and A. F. Hayes, "Asymptotic and resampling strategies for assessing comparing indirect effects in multiple mediator models," Behavioural Research Methods, vol. 40, pp. 879$891,2008$.

[73] K. J. Preacher and A. F. Hayes, "SPSS and SAS procedures for estimating indirect effects in simple mediation models," Behaviour Research Methods, Instruments, and Computers, vol. 36, pp. 717-731, doi:10.3758/BF03206553, 2004.

[74] J. Reason, "Managing the risks of organizational accidents," Aldershot, Hants, England: Ashgate Publishing, 1997.

[75] J. Reason, "Human error: Models and management," British Medica Journal, vol.32, pp.768-770, 2000.

[76] M. Rubin, A. Giacomini, R. Allen, R. Turner and B. Kelly, "Identifying safety culture and safety climate variables that predict reported risk-taking among Australian coal miners: An exploratory longitudinal study," Safety Science, vol. 123, no.104564, pp.1-9, doi.org/10.1016/j.ssci.2019.104564, 2020.

[77] A. Salleh, "Safety behaviour in the Malaysian petrochemical industry", (PhD thesis), University Utara, Malaysia, 2010.

[78] F. Scheuren, "What is a Survey?" American Statistical Association, 2004.

[79] S. Silva, M. L. Lima and C. Baptista, "OSCI: An organisational and safety climate inventory," Safety Science, vol. 42, pp. 205-220, 2004.

[80] R. Singleton and B. C. Straits, "Approaches to social research," New York: Oxford University Press, 2010.

[81] A. P. Smith and E. J. Wadsworth, "Safety culture, advice and performance," Cardiff, Centre for Occupational and Health Psychology, Cardiff University, 2009.

[82] D. Soper, (2016), "A-priori sample size calculator for multiple regressions," 2016, Available: www.danielsoper.com.

[83] B. G. Tabachnick and I.S. Fidell, "Using multivariate statistics (6th ed.), Boston: Pearson Education, 2013.

[84] C. Taylor, "Sources of the self: The making of the modern identity," Harvard University Press, 1989.

[85] US Department of Labour, The Latino labour force at a glance, "US Bureau of Labour Statistics," Current Population Survey: Author, 2012.

[86] A. G. Vredenburgh, "Organizational safety: which management practices are most effective in reducing employee injury rates?' Journal of safety Research, vol.33, no.2, pp. 259-276, 2002.

[87] C. Williams, "Sky service: The demands of emotional labour in the airline industry," Gender, Work \& Organization, vol.10 no. 5, pp. 513-550, 2003

[88] A. Zacharatos, J. Barling, and R.D. Iverson, "High-performance work systems and occupational safety," Journal of Applied Psychology, vol. 90 no 1 , pp.77-93, 2005

[89] D. Zohar, 'Thirty years of safety climate research: Reflections and future directions," Accident Analysis and Prevention, vol. 42 no.5, pp.1517-1522, 2010.
[90] D. Zohar, "The effects of leadership dimensions, safety climate, and assigned priorities on minor injuries in work groups," Journal of Organizational Behaviour, vol. 23, pp. 75-92, 2002.

[91] D. Zohar, "A group-level model of safety climate: testing the effect of group climate on micro accidents in manufacturing jobs," Journal of Applied Psychology, vol. 85, no. 4, pp. 587-596, 2000.

Lebbaeus Asamani, Ph.D is a Ghanaian, and Senior Lecturer at the Department of Education and Psychology, University of Cape Coast, Ghana. He holds an MPhil (2007), and a Ph.D (2017) in Industrial and Organisational Psychology from the University of Ghana, Legon. He also obtained a Post Graduate Diploma in Education (2014) from the University of Cape Coast. He has published widely in the area of Psychology and Education in peer-reviewed Journal.

Dr. Asamani is a member of the Ghana Psychology Association (GPA), and the University Teachers Association of Ghana (UTAG). 